\title{
Three-dimensional printing of biomaterials and soft materials
}

\author{
Amit Bandyopadhyay, Sahar Vahabzadeh, Anish Shivaram, and \\ Susmita Bose
}

During the past two decades, numerous biomaterials and soft materials, including ceramics, polymers, and their composites, have been fabricated for various biomedical devices and applications in tissue engineering using three-dimensional (3D) printing. This article offers a brief overview of some of the biomaterials and soft materials fabricated using some notable 3D printing techniques and related applications. A brief perspective regarding future directions of this field is also provided.

\section{Introduction}

Three-dimensional (3D) printing, which is also known as additive manufacturing, solid freeform fabrication, or rapid prototyping, is a layer-by-layer fabrication method for creating structures directly from computer-aided design (CAD) files. In 3D printing techniques, a 3D CAD model is first converted into a standard tessellation language (.STL) file format and then sliced in a virtual environment to create stacked two-dimensional (2D) sections along the height. A 3D printer builds each 2D layer based on the slice-file information, starting from the base and continuing to build layer-by-layer on top of previously built layers until the final product is printed.

Three-dimensional printing first emerged in 1986 through a stereolithography (SLA) technique devised by Hull. ${ }^{1}$ In 1991, Stratasys ${ }^{2}$ and Helisys ${ }^{3}$ commercially introduced fused deposition modeling (FDM) and laminated object manufacturing, respectively. Later, in 1992, DTM Corporation introduced a selective laser sintering (SLS) machine. ${ }^{4}$ Sachs et al. invented inkjet 3D printing on a powder bed and patented this method in $1993 .{ }^{5}$ Over the past 25 years, 3D printing has seen several commercial implementations, but the FDM-based concept still leads the world in terms of purchased machines, broader utilization, and applications. Some other techniques have recently found commercial success for the fabrication of soft materials, such as multijet fusion by HP and large-area maskless photopolymerization (LAMP) by DDM Systems (Atlanta, Ga).

Three-dimensional printing of biomaterials has become an area of intense research (see the February 2015 issue of the MRS Bulletin devoted to this topic). It offers the chance to fabricate parts with complex geometries for flexible biomedical devices tailored to a patient's specific needs while avoiding multistep processing approaches. Over the past two decades, the use of 3D-printed biomaterials for tissue-engineering (TE) applications has offered significant advantages by employing a large variety of materials for the printing of one-of-a-kind structures. Also, incorporation of living cells during processing adds another advantage over other scaffold fabrication approaches.

\section{D printing technologies for biomaterials and soft materials}

This section summarizes some of the key 3D printing technologies and their applications in biomaterials and soft materials (see Table I). ${ }^{6-28}$

\section{Stereolithography}

SLA, the first commercially available 3D printing process, involves selective laser curing of photopolymers based on the slice-file information from a CAD model. ${ }^{29}$ In exposed areas, 
Table I. Three-dimensional printing of biomaterials and soft materials. *

\begin{tabular}{|c|c|c|c|}
\hline Composition & 3DP Process(es) & Application & Reference(s) \\
\hline PPF/DEF & SLA & Bone tissue engineering & 6 \\
\hline PLGA-embedded PPF/DEF & SLA & Drug delivery & 7 \\
\hline Chitosan & SLA & Bone tissue engineering & 8,9 \\
\hline Hydrogels (GelMA) & SLA & Tissue engineering & 10 \\
\hline PCL & FDM, SLS, SLA & Tissue engineering & $11-14$ \\
\hline PLA & FDM & Tissue engineering & 12 \\
\hline PLGA & FDM & Bone tissue engineering & 15 \\
\hline Hydroxyl-functionalized PCL & Ink writing & Tissue engineering & 16 \\
\hline TCP & Ink writing & Bone tissue engineering & 17 \\
\hline HA/PDLLA & SLA & Bone tissue engineering & 8 \\
\hline $\mathrm{HA}$ in PPF/DEF & SLA & Bone tissue engineering & 9 \\
\hline Bioglass/PCL & SLA, FDM & Tissue engineering & 10,12 \\
\hline PEGT/PBT & FDM & Cartilage tissue engineering & 15 \\
\hline$\beta$-TCP/PLGA & FDM & Bone tissue engineering & 18 \\
\hline TCP/PP & FDM & Tissue engineering & 19 \\
\hline HA/PEEK & SLS & Tissue engineering & 20 \\
\hline PLLA and PHBV & SLS & Tissue engineering & 21 \\
\hline HA/PVA & SLS & soft tissue engineering & 22 \\
\hline TCP/collagen & Bioplotting & Tissue engineering & 23 \\
\hline Collagen/alginate/silica/HA & Bioplotting & Hard tissue engineering & 24 \\
\hline Alginate and gelation & Bioplotting & Pancreas tissue engineering & 25 \\
\hline PLLA/PLGA & $L A B$ & Liver tissue engineering & 26 \\
\hline MSC-embedded alginate/hydrogel & Bioprinting & Tissue engineering & 27 \\
\hline Sodium alginate/HA & Bioprinting & Tissue engineering & 28 \\
\hline
\end{tabular}

*Acronyms: 3DP, three-dimensional printing; DEF, diethyl fumarate; FDM, fused deposition melting HA, hydroxyapatite; LAB, laser-assisted bioprinting; MSC, multipotent stromal cell; PBT, poly (butylene terephthalate); PCL, poly( $\varepsilon$-caprolactone); PDLLA, poly(D,L-lactic acid); PEEK, poly(ether ether ketone); PEGT, poly(ethylene glycol terephthalate); PHBV, poly(hydroxybutyrate-co-hydroxyvalerate); PLA, poly(lactic acid); PLGA, poly(D,L-lactic-co-glycolic acid); PP, polypropylene; PPF, poly(propylene fumarate); PVA, poly(vinyl alcohol); SLA, stereolithography; SLS, selective laser sintering; ( $\beta$-)TCP, $(\beta-)$ tricalcium phosphate.

the polymer cures and solidifies as a result of cross-linking, but it remains liquid at unexposed sites (Figure 1a). This process is still very popular for soft materials, and inclusion of hard materials, mainly ceramic structures, is allowed through the use of particle-loaded photopolymers as in the LAMP process. The main application of SLA in the field of biomaterials is scaffolds for TE. ${ }^{31-33}$ However, the fact that only a few biocompatible polymers are stable under exposure to laser light has become one of the major limitations for broad application of SLA in TE.

Poly(propylene fumarate) (PPF), a biodegradable polymer, has been widely used in bone TE because of its biocompatibility, injectability, and good mechanical properties. PPF is generally processed by SLA, using diethyl fumarate
(DEF) as the solvent and bis(acyl) phosphine oxide as the photoinitiator. To achieve the desired structure, different parameters, such as solution viscosity, laser speed, and power, must be optimized. ${ }^{6}$

Localized delivery of drugs is another important application for biomedical engineering. Drugs can be incorporated into 3D structures and released in a controlled manner to increase the efficiency of treatment and decrease side effects involving other tissues. For example, Lee et al. embedded bone morphogenetic protein-2 (BMP-2), a protein with a stimulating effect for new bone formation in vitro and in vivo, in poly(D,L-lacticco-glycolic acid) (PLGA) microspheres suspended in a PPF/DEF photopolymer. They then used $3 \mathrm{D}$ printing via SLA to create a scaffold that enabled the gradual release of BMP-2. These 3D-printed scaffolds enhanced new bone formation in vivo compared to scaffolds made by the traditional particulate leaching/gasfoaming method.?

Chitosan, a natural polymer, is also used in medical applications because of its biodegradability and biocompatibility and is a good candidate for orthopedic applications involving cartilage and bone TE. To process chitosan using SLA, Irgacure 2959, a photoinitiator composed of unsaturated monomers and prepolymers, and poly(ethylene glycol) diacrylate were added to the polymer solution to enhance its photosensitivity. ${ }^{8,9}$ The fabricated scaffolds exhibited in vitro cytocompatibility in the presence of fibroblast cells and enhanced bone tissue growth in vivo. ${ }^{9}$

Recently, custom-designed projection stereolithography (PSL) was introduced for the fabrication of multiple biomaterials for TE applications. ${ }^{10}$ In PSL, instead of the scanned laser used in SLA, a digital light-processing chip is used to create photomasks from a CAD file to produce 2D slices based on 3D structures. Collagen-based gelatin methacrylate (GelMA) hydrogels were successfully processed by PSL, with methacrylamide enabling photopolymerization of the hydrogel. GelMA hydrogels of different structures (e.g., hexagonal and woodpile) with precisely controlled pore sizes were fabricated to support adhesion and proliferation of human umbilical vein endothelial cells (HUVECs), confirming the functionality of hydrogels in TE applications. ${ }^{10}$ 


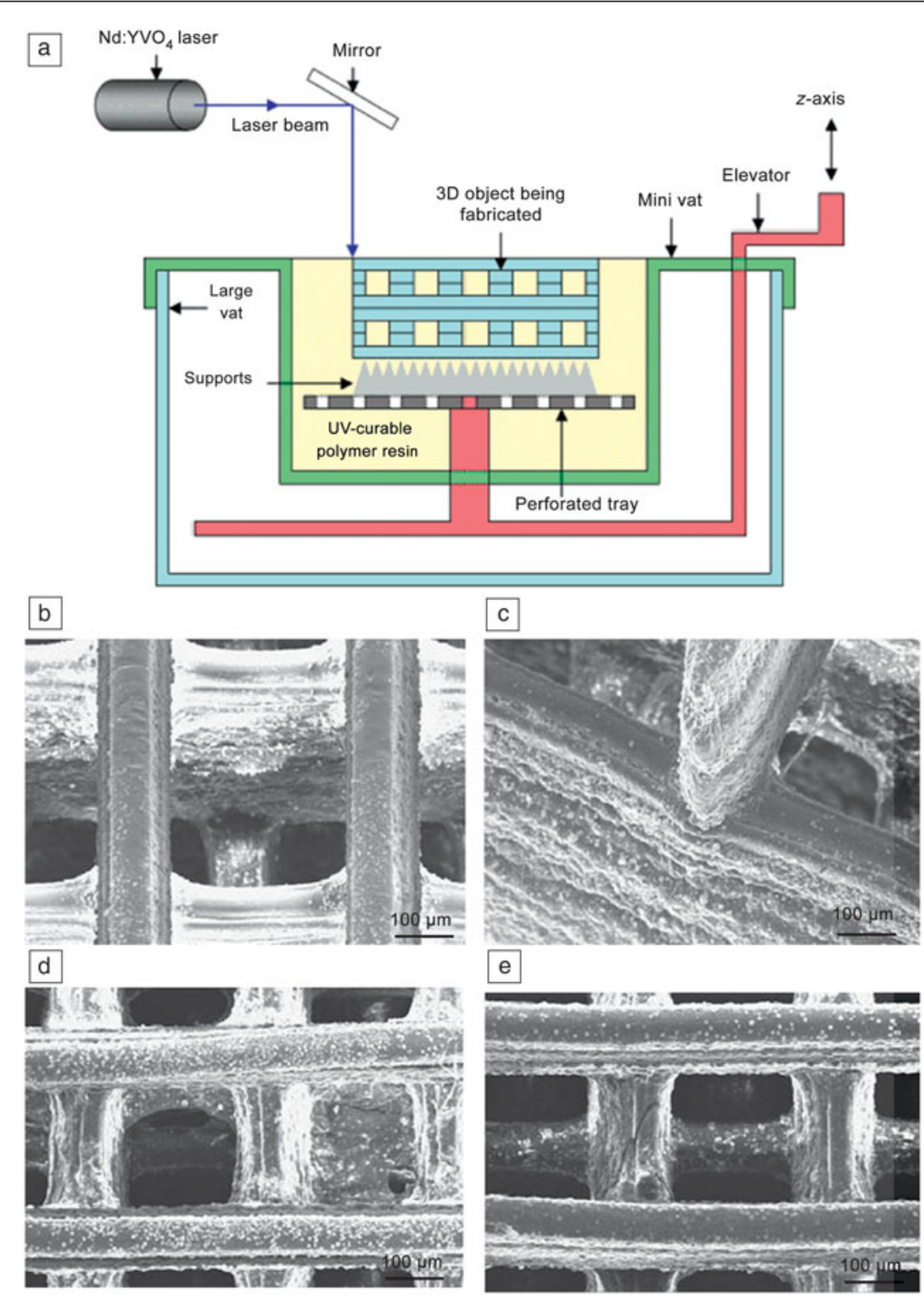

Figure 1. (a) Schematic of a stereolithography system. ${ }^{6}(b-c)$ Scanning electron microscope images of a poly(propylene fumarate)/diethyl fumarate-hydroxyapatite (PPF/DEF-HA) scaffold processed by microstereolithography and of $(d-e)$ pre-osteoblast cells in a PPF/DEFHA scaffold. ${ }^{30}$ (a) Reproduced with permission from Reference 6. () 2007 American Chemical Society. (b-e) Reproduced with permission from Reference 30. (c) 2009 Elsevier.

of the composites increased with increasing concentration of HA nanoparticles. ${ }^{34}$ Threedimensional composites containing 7\% HA nanoparticles in 70:30 PPF/DEF were found to be suitable for SLA processing and to result in enhanced bone-cell attachment and proliferation (Figure 1b-e). ${ }^{30}$ SLA-printed biodegradable and bioactive glass/methacrylated poly( $\varepsilon$-caprolactone) (PCL) composite has also shown potential in regenerative medicine, because of an increased deposition of calcium phosphate and an enhanced metabolic activity of fibroblast cells. ${ }^{35}$

\section{Fused deposition modeling}

Similar to SLA, FDM was originally used to fabricate $3 \mathrm{D}$ polymeric structures. In the FDM process, a thermoplastic polymer filament passes through a heated liquefier and is then extruded through a nozzle. The extrusion head moves along the $x$ and $y$ axes to deposit material. ${ }^{36}$ The method was later modified to fabricate ceramic and ceramic/polymer composites, in a process termed fused deposition of ceramics. ${ }^{37}$

Numerous polymeric structures have been processed using FDM; however, only a few of them are biocompatible or can be directly used in biomedical applications, such as acrylonitrile butadiene styrene (ABS), which can be sterilized with $\gamma$-radiation or ethylene oxide treatment. ${ }^{38} \mathrm{PCL}$ is one of the most studied biopolymers for use in FDM. For example, Zein et al. produced 3D PCL structures with a variety of channel sizes, filament diameters, and porosities and found a significant correlation between compressive strength and porosity. ${ }^{11}$ Korpela et al. processed poly(lactic acid) (PLA), PCL, PCL/bioactive glass, and poly(Llactide-co- $\varepsilon$-caprolactone) (PLC) copolymer using FDM. Processing of both PCL and PLA was simple; however, the addition of bioactive glass increased the viscosity of PCL, and the FDM of PLC was interrupted frequently

In addition to soft biomaterials, hard biomaterials such as ceramics and ceramic/polymer composites have also been fabricated using SLA. Hydroxyapatite (HA) nanopowders embedded in poly(D,L-lactide) oligomers were processed for bone $\mathrm{TE}^{34}$ using ethyl-2,4,6-trimethylbenzoylphenyl phosphinate and $N$-methyl-2-pyrrolidone as the photoinitiator and diluent, respectively. Small amounts of tocopherol inhibitor and Orange Orasol G dye were also added to prevent premature polymerization and to set the requisite light penetration depth, respectively. The results showed that the amounts of HA nanoparticles and diluents had significant effects on the viscosity of the resins. In addition, the modulus of elasticity because of high viscosity and filament buckling. All compositions supported cell attachment and proliferation, but fibroblast proliferation was the highest for PLA scaffolds. ${ }^{12}$

Three-dimensional poly(ethylene glycol terephthalate)/ poly(butylene terephthalate) block copolymer scaffolds with varying porosities and pore sizes were also successfully produced for cartilage TE. The deposited scaffolds supported chondrocyte attachment and distribution and encouraged the deposition of articular cartilage extracellular matrix in a nude mouse model. ${ }^{15}$

FDM has been used directly and indirectly to make scaffolds for bone TE applications. ${ }^{39-41}$ Alumina 3D-printed scaffolds have been processed by FDM to support attachment and 
proliferation of human osteoblast cells. ${ }^{42,43}$ FDM-processed PLGA is another promising material for bone TE applications because of its interaction with the L-929 fibroblast cell line and increased bone formation in an in vivo rabbit tibia model. ${ }^{44}$ PLGA/ $\beta$-tricalcium phosphate $(\beta$-TCP) composites with simple and complex structures were processed by FDM and coated with HA. After 12 weeks postimplantation, with or without HA coating, samples were biocompatible and supported bone deposition. ${ }^{18}$ Complex TCP/polypropylene (PP) microstructures (see Figure 2a) have been investigated for bone TE applications because their mechanical properties are similar to those of cancellous bone, the spongy inner part of bone, and because they have the ability to support attachment and proliferation of human osteoblast cells. ${ }^{19}$

\section{Selective laser sintering}

SLS uses a powder bed in which each layer is built by sintering using a laser directed by a CAD model. This technique is commonly used for manufacturing both metallic and nonmetallic parts. Common nonmetallic biomaterials include ceramics such as TCP, HA, alumina, and zirconia and polymers such as PCL, PP, poly(ether ether ketone) (PEEK), and polyamide 12 . PCL scaffolds, ${ }^{13}$ scaffolds made of PEEK/ HA biocomposite blends, ${ }^{20}$ and interconnected porous scaffolds using calcium phosphates and polymers such as PLA and poly(hydroxybutyrate-co-hydroxyvalerate) (PHBV) (see Figure $2 b)^{21}$ have been fabricated using SLS for TE-related applications. Recent advances in SLS have allowed the production of scaffolds for craniofacial and joint defect applications, as well as for the fabrication of low-stiffness porous scaffolds for soft-tissue applications such as cardiac tissues using PCL and poly(vinyl alcohol) (PVA) with HA. ${ }^{14,22,46}$

\section{Bioplotting/3D plotting}

Bioplotting is an extrusion-based 3D dispensing technique that uses a pressure-controlled dispenser that can be moved in three dimensions to fabricate materials layer by layer on an aqueous medium, thus achieving buoyancy compensation without a support structure. ${ }^{47}$ Bioplotting can be employed for a wide range of materials, mainly in the form of hydrogels, which facilitates the fabrication of complex internal substructures. The main advantage of this technique is its use of natural polymers, such as chitosan, alginate, and collagen, as fabrication materials. Other biomaterials commonly used

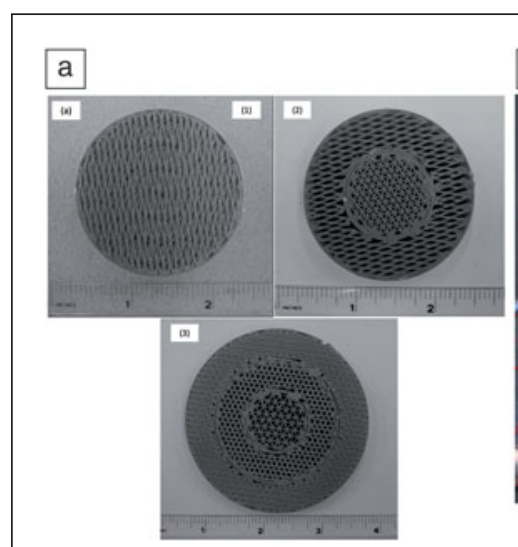

d

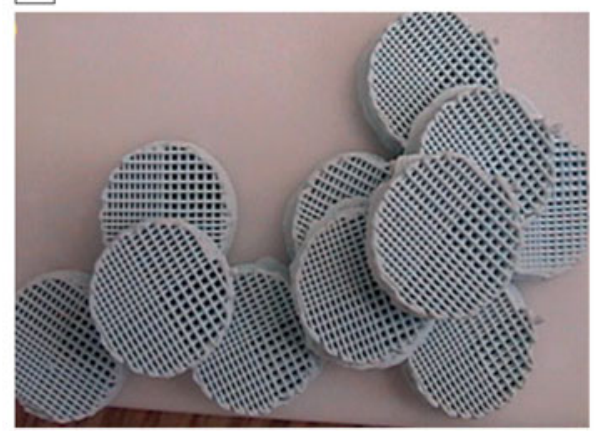

\section{b}

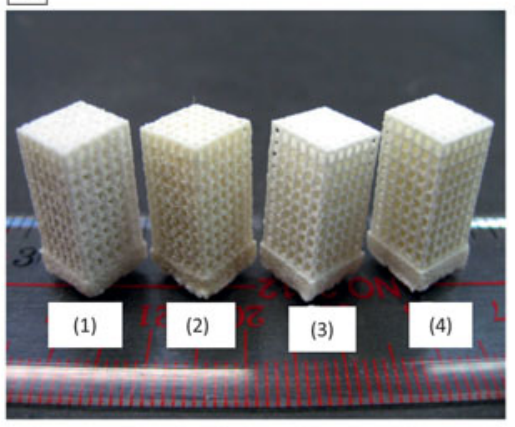

c

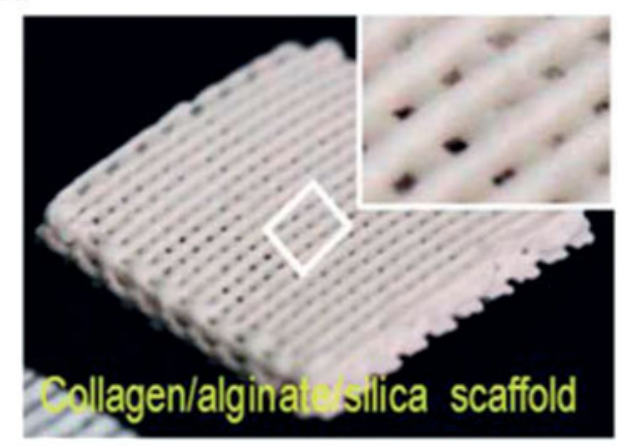

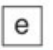

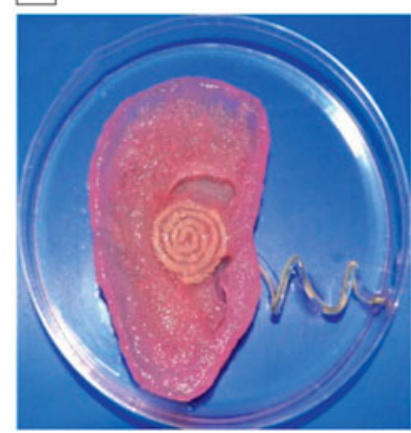

Figure 2. (a) Fused deposition modeling-processed porous tricalcium phosphate/polypropylene scaffolds with (1) complex and (2,3) gradient-controlled porosity. ${ }^{19}$ (b) Scaffolds produced by selective laser sintering: (1) poly(hydroxybutyrate-co-hydroxyvalerate) (PHBV), (2) calcium phosphate/PHBV, (3) poly(L-lactic acid) (PLLA), (4) carbonated hydroxyapatite/PLLA. ${ }^{21}$ (c) Bioplotted collagen/alignate/silica scaffold. ${ }^{24}$ (d) 3D-printed hydroxyapatite scaffolds fabricated using direct ink writing. ${ }^{16}$ (e) 3D-printed bionic ear. ${ }^{45}$ (a) Reproduced with permission from Reference 19. () 2003 Elsevier. (b) Reproduced with permission from Reference 21. (C) 2010 Elsevier. (c) Reproduced with permission from Reference 24. (c) 2014 Royal Society of Chemistry. (d) Reproduced with permission from Reference 16. (c) 2007 Wiley. (e) Reproduced with permission from Reference 45. (c) 2013 American Chemical Society. 
for this process include polymers such as PCL, PVA, and poly(L-lactic acid) (PLLA) and ceramics such as HA, TCP, bioglass, and their composites.

Haberstroh et al. demonstrated the bioplotting of composite scaffolds made of collagen-treated TCP, TCP/chitosan/ collagen hydrogel, and PLGA for ovine critical-sized calvarial defects. ${ }^{23}$ Fabrication of collagen/alginate/silica composite scaffolds (see Figure 2c) using a low-temperature bioplotting process for hard-tissue regeneration ${ }^{24}$ and of 3D hydrogel scaffolds composed of alginate and gelatin for application in pancreas $\mathrm{TE}^{25}$ has also been achieved. Thus, scaffolds fabricated using $3 \mathrm{D}$ bioplotting can incorporate living cells and facilitate the growth of tissues. Efforts are being made to improve the process and make it more widely applicable in TE. For example, Kim et al. modified a 3D bioplotting system by introducing a piezoelectric transducer that generated vibrations while fabricating PCL scaffolds, resulting in a rougher surface finish for improved cell attachment. ${ }^{48}$

\section{Direct ink writing}

Direct ink writing or direct write assembly is a broad term describing fabrication methods that use computer-aided programs to print 3D structures using a nozzle to form droplets on a powder bed. Specifically, this process is similar to binder jetting, which selectively deposits powder material using a liquid bonding agent. A variety of materials, including HA (see Figure $2 \mathrm{~d}^{16}$ ), TCP, PCL, and many other polymers, can be processed using this method. ${ }^{17,26,27,49}$ This process controls the composition of printed parts by using predetermined volumes of the appropriate binder, thus resulting in patterned parts with the desired densities and uniformities. Therefore, with direct ink writing, complex structures can be printed with programmed porosities, as seen in Figure 3a-c. ${ }^{17,26,49,50}$

Calcium phosphate scaffolds for early-stage osteogenesis have been fabricated using this process ${ }^{26}$ (see Figure $3 d-f$ ). Hydroxyl-functionalized PCL structures for TE applications ${ }^{27}$ and 3D-printed mesoporous bioactive glass scaffolds with improved mechanical properties and controlled pore architecture for bone regeneration applications ${ }^{28}$ have also been reported. Although direct ink writing allows the fabrication of complex parts with designed porosities and interconnected porous structures, the difficulty of selecting the appropriate binder during processing and the inability to print porous structures with pore sizes smaller than $300 \mu \mathrm{m}$ are major drawbacks of this technique. Additional post-processing techniques might also be required, such as sintering, which could lead to part shrinkage, thus illustrating the need for process optimization.

\section{Laser-assisted bioprinting}

Laser-assisted bioprinting (LAB) is a fabrication process for hydrogel structures that affords the direct incorporation of cells. In LAB, a laser pulse is used to control the deposition of material onto transparent quartz disks, called ribbons. A wide variety of materials such as HA; PLA; PCL; zirconia; and hydrogels with incorporated living cells such as human osteoblast cells, human umbilical vein smooth cells, and multipotent stromal cells (MSCs) (an example of which can be seen in Figure 2e $)^{45}$ can be fabricated. Material processing at ambient temperatures and direct incorporation of cells with a homogeneous distribution are two of the main advantages of LAB. Low mechanical stiffness and the requirement for homogeneous ribbons are potential disadvantages of this process. 3D-printed PLLA/PLGA scaffolds with a mixture of hepatocytes and endothelial cells have been investigated for organogenesis of liver tissue. ${ }^{51}$ Also, high cell viability was observed for MSCs embedded in a printed alginate/hydrogel composite, demonstrating extracellular matrix formation both in vitro and in vivo. ${ }^{53}$ Guillemot et al. reported the fabrication of sodium alginate/HA composites with human endothelial cells for TE applications using high-throughput laser bioprinting. ${ }^{54}$ HUVECs embedded in glycerol/sodium alginate solution at various viscosities and cell densities were produced using LAB for tissue fabrication. ${ }^{52,54}$

\section{Current challenges and future directions}

Three-dimensional printing offers various advantages in the fabrication of biomaterials and has become a versatile and popular manufacturing tool for applications involving soft materials. However, different 3D printing techniques have certain advantages and drawbacks, and a good understanding of each process is needed before selection for a specific application. For 3D printing of biomaterials, a sterile fabrication environment is a major issue for some processes. Maintaining cell viability and printing complex 3D parts adds an extra set of challenges that is still being researched. Finally, part accuracy and reproducibility are continuing issues with most $3 \mathrm{D}$ printers. ${ }^{55}$

The field of soft-material 3D printing is quite advanced. Large FDM-based printers that can print objects as substantial as cars are now commercially available. However, surface finish can be an issue for large parts, for which slice thickness is usually kept large to reduce the build time.

Future directions for 3D printing lie with multimaterial and gradient parts that cannot be created using conventional manufacturing. Three-dimensional printing offers designers capabilities that were not previously available. Therefore, full utilization of 3D printing will come when parts are designed specifically to capitalize on the strengths of the technique and not merely because they are not easily fabricated using conventional tools. The addition of polymers with ceramics to aid in drug delivery, variation in composition to tailor cell-materials interactions, and mechancical properties are some of the concept that will evolve as the next-generation $3 \mathrm{D}$ printed scaffolds. ${ }^{56,57}$ Simultaneous deposition of multiple materials offering unique properties and functionalities will lead to a manufacturing revolution in the coming years with the help of $3 \mathrm{D}$ printing.

\section{Acknowledgments}

The authors thank the W.M. Keck Foundation, M.J. Murdock Charitable Trust, National Institutes of Health (NIH, Grant AR066361-01A1), and Life Sciences Discovery Fund (LSDF) for their financial support. 


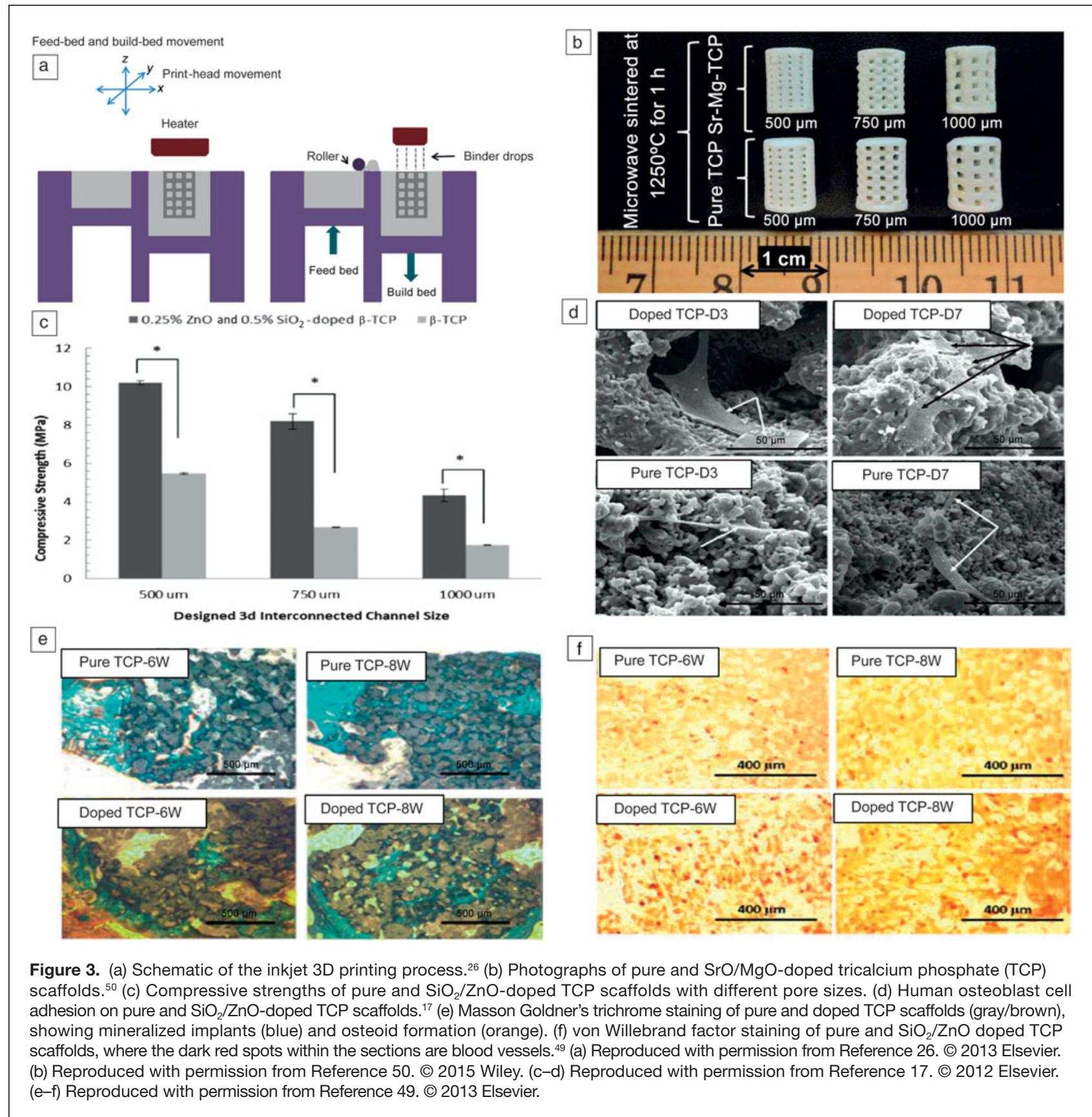

\section{References}

1. C.W. Hull (UVP, Inc.), "Apparatus for Production of Three-Dimensional Objects by Stereolithography," US Patent 4,575,330 (1984).

2. Stratasys Home Page, http://www.stratasys.com (accessed July 2015).

3. A. Das, G. Madras, N. Dasgupta, A.M. Umarji, J. Eur. Ceram. Soc. 23 (7), 1013 (2003).

4. A. Lou, C. Grosvenor, "Selective Laser Sintering, Birth of an Industry" (Department of Mechanical Engineering, University of Texas, Austin, TX, December 7, 2012), http://www.me.utexas.edu/news/2012/0712_sls_history. php (accessed July 2015).

5. E.M. Sachs, J.S. Haggerty, M.J. Cima, P.A. Williams (Massachusetts Institute of Technology), "Three-Dimensional Printing Techniques," US Patent 5,204,055 (1993).

6. K.-W. Lee, S. Wang, B.C. Fox, E.L. Ritman, M.J. Yaszemski, L. Lu, Biomacromolecules 8, 1077 (2007).

7. J.W. Lee, K.S. Kang, S.H. Lee, J.Y. Kim, B.K. Lee, D.W. Cho, Biomaterials 32 , 744 (2011)
8. T.A. Akopova, T.S. Demina, V.N. Bagratashvili, K.N. Bardakova, M.M. Novikov, I.I. Selezneva, A.V. Istomin, E.A. Svidchenko, G.V. Cherkaev, N.M. Surin, P.S. Timashev, IOP Conf. Ser. Mater. Sci. Eng. 87, 012079 (2015). 9. Y. Qiu, N. Zhang, Q. Kang, Y. An, X. Wen, J. Biomed. Mater. Res. A 89 (3), 772 (2009).

10. R. Gauvin, Y.C. Chen, J.W. Lee, P. Soman, P. Zorlutuna, J.W. Nichol, H. Bae, S. Chen, A. Khademhosseini, Biomaterials 33 (15), 3824 (2012).

11. I. Zein, D.W. Hutmacher, K.C. Tan, S.H. Teoh, Biomaterials 23, 1169 (2002). 12. J. Korpela, A. Kokkari, H. Korhonen, M. Malin, T. Närhi, J. Seppälä, J. Biomed. Mater. Res. B 101 (4), 610 (2013)

13. J.M. Williams, A. Adewunmi, R.M. Schek, C.L. Flanagan, P.H. Krebsbach, S.E. Feinberg, S.J. Hollister, S. Das, Biomaterials 26, 4817 (2005).

14. W.Y. Yeong, N. Sudarmadji, H.Y. Yu, C.K. Chua, K.F. Leong, S.S. Venkatraman, Y.C.F. Boey, L.P. Tan, Acta Biomater. 6, 2028 (2010).

15. T.B.F. Woodfield, J. Malda, J. de Wijn, F. Peters, J. Riesle, C.A. van Blitterswijk, Biomaterials 25, 4149 (2004).

16. J.L. Simon, S. Michna, J.A. Lewis, E.D. Rekow, V.P. Thompson, J.E. Smay, A. Yampolsky, J.R. Parsons, J.L. Ricci, J. Biomed. Mater. Res. A 83, 747 (2007). 
17. G.A. Fielding, A. Bandyopadhyay, S. Bose, Dent. Mater. 28, 113 (2012). 18. J. Kim, S. McBride, B. Tellis, P. Alvarez-Urena, Y.H. Song, D.D. Dean, V.L. Sylvia, H. Elgendy, J. Ong, J.O. Hollinger, Biofabrication 4, 025003 (2012).

19. S.J. Kalita, S. Bose, H.L. Hosick, A. Bandyopadhyay, Mater. Sci. Eng. C 23, 611 (2003).

20. K.H. Tan, C.K. Chua, K.F. Leong, C.M. Cheah, P. Cheang, M.S. Abu Bakar, S.W. Cha, Biomaterials 24, 3115 (2003).

21. B. Duan, M. Wang, W.Y. Zhou, W.L. Cheung, Z.Y. Li, W.W. Lu, Acta Biomater. 6, 4495 (2010).

22. C. Chua, K. Leong, K. Tan, F. Wiria, C. Cheah, J. Mater. Sci. Mater. Med. 15, 1113 (2004)

23. K. Haberstroh, K. Ritter, J. Kuschnierz, K.-H. Bormann, C. Kaps, C. Carvalho, R. Mülhaupt, M. Sittinger, N.-C. Gellrich, J. Biomed. Mater. Res. B93 (2), 520 (2010). 24. H.-J. Lee, Y.-B. Kim, S.-H. Kim, G.-H. Kim, J. Mater. Chem. B2, 5785 (2014). 25. G. Marchioli, L. van Gurp, P.P. van Krieken, D. Stamatialis, M. Engelse, C.A. van Blitterswijk, M.B.J. Karperien, E. de Koning, J. Alblas, L. Moroni, Biofabrication 7, 025009 (2015)

26. S. Bose, S. Vahabzadeh, A. Bandyopadhyay, Mater. Today 16 (12), 496 (2013). 27. H. Seyednejad, D. Gawlitta, R.V. Kuiper, A. de Bruin, C.F. van Nostrum, T. Vermonden, W.J.A. Dhert, W.E. Hennink, Biomaterials 33, 4309 (2012).

28. C. Wu, Y. Luo, G. Cuniberti, Y. Xiao, M. Gelinsk, Acta Biomater. 7, 2644 (2011).

29. J.P. Fisher, D. Dean, A.G. Mikos, Biomaterials 23, 4333 (2002).

30. J.W. Lee, G. Ahn, D.S. Kim, D.W. Cho, Microelectron. Eng. 86, 1465 (2009). 31. H.W. Kang, D.W. Cho, Tissue Eng. C 18, 719 (2012).

32. J.H. Park, J.W. Jung, H.W. Kang, D.W. Cho, Biofabrication 6, 025003 (2014). 33. H.N. Chia, B.M. Wu, J. Biol. Eng. 9 , 4 (2015).

34. A. Ronca, L. Ambrosio, D.W. Grijpma, Acta Biomater. 9, 5989 (2013).

35. L. Elomaa, A. Kokkari, T. Närhi, J.V. Seppälä, Compos. Sci. Technol. 74, 99 (2013). 36. E.A. Griffin, S. McMillin, "Selective Laser Sintering and Fused Deposition Modeling Processes for Functional Ceramic Parts," Proc. Solid Freeform Fabrication (University of Texas, Austin, TX, 1995), pp. 25-30.

37. M. Agarwala, A. Bandyopadhyay, S.C. Danforth, V.R. Jamalabad, N. Langrana, W.R. Priedeman, A. Safari, R. van Weeren (Rutgers University), "Solid Freeform Fabrication Methods," US Patent 5,900,207 (1999).
38. L. Novakova-Marcincinova, I. Kuric, Manuf. Ind. Eng. 11 (1), 24 (2012) 39. S. Bose, S. Sugiura, A. Bandyopadhyay, Scr. Mater. 41 (9), 1009 (1999). 40. S. Bose, J. Darsell, L. Yag, D.K. Sarkar, H.L. Hosick, A. Bandyopadhyay, J. Mater. Sci. Mater. Med. 13, 23 (2002)

41. S.J. Kalita, S. Bose, A. Bandyopadhyay, H.L. Hosick, J. Mater. Res. 17, 3042 (2002).

42. J. Darsell, S. Bose, H. Hosick, A. Bandyopadhyay, J. Am. Ceram. Soc. 86 (7), 1076 (2003)

43. S. Bose, J. Darsell, M. Kintner, H. Hosick, A. Bandyopadhyay, Mater. Sci. Eng. C 23, 479 (2003).

44. S.H. Park, D.S. Park, J.W. Shin, Y.G. Kang. H.K. Kim, T.R. Yoon, J.W. Shin, J. Mater. Sci. Mater. Med. 23, 2671 (2012).

45. M.S. Mannoor, Z. Jiang, T. James, Y.L. Kong, K.A. Malatesta, W.O. Soboyejo,

N. Verma, D.H. Gracias, M.C. McAlpine, Nano Lett. 13 (6), 2634 (2013).

46. B. Partee, S.J. Hollister, S. Das, J. Manuf. Sci. Eng. 128, 531 (2006)

47. R. Landers, R. Mülhaupt, Macromol. Mater. Eng. 282, 17 (2000).

48. G.H. Kim, J.G. Son, Appl. Phys. A 94, 781 (2009).

49. S. Bose, G. Fielding, Acta Biomater. 9 (11), 9137 (2013).

50. S. Tarafder, W.S. Dernell, A. Bandyopadhyay, S. Bose, J. Biomed. Mater. Res. B 103, 679 (2015).

51. L.G. Griffith, B. Wu, M.J. Cima, M.J. Powers, B. Chaignaud, J.P. Vacanti, Ann. N.Y. Acad. Sci. 831, 382 (1997).

52. B. Guillotin, A. Souquet, S. Catros, M. Duocastella, B. Pippenger, S. Bellance, R. Bareille, M. Rémy, L. Bordenave, J. Amédée, Biomaterials 31, 7250 (2010)

53. N.E. Fedorovich, W. Schuurman, H.M. Wijnberg, H.-J. Prins, P.R. van Weeren, J. Malda, J. Alblas, W.J.A. Dhert, Tissue Eng. C 18, 33 (2012). 54. F. Guillemot, A. Souquet, S. Catros, B. Guillotin, J. Lopez, M. Faucon, B. Pippenger, R. Bareille, M. Rémy, S. Bellance, P. Chabassier, J.C. Fricain J. Amédée, Acta Biomater. 6, 2494 (2010)

55. A. Bandyopadhyay, S. Bose, S. Das, MRS Bull. 40 (2), 108 (2015).

56. S. Tarafder, S. Bose, ACS Appl. Mater. Interfaces 6 (13), 9955 (2014).

57. S. Bose, S. Tarafder, S.S. Banerjee, N.M. Davies, A. Bandyopadhyay, Bone 48 (6), 1282 (2011).

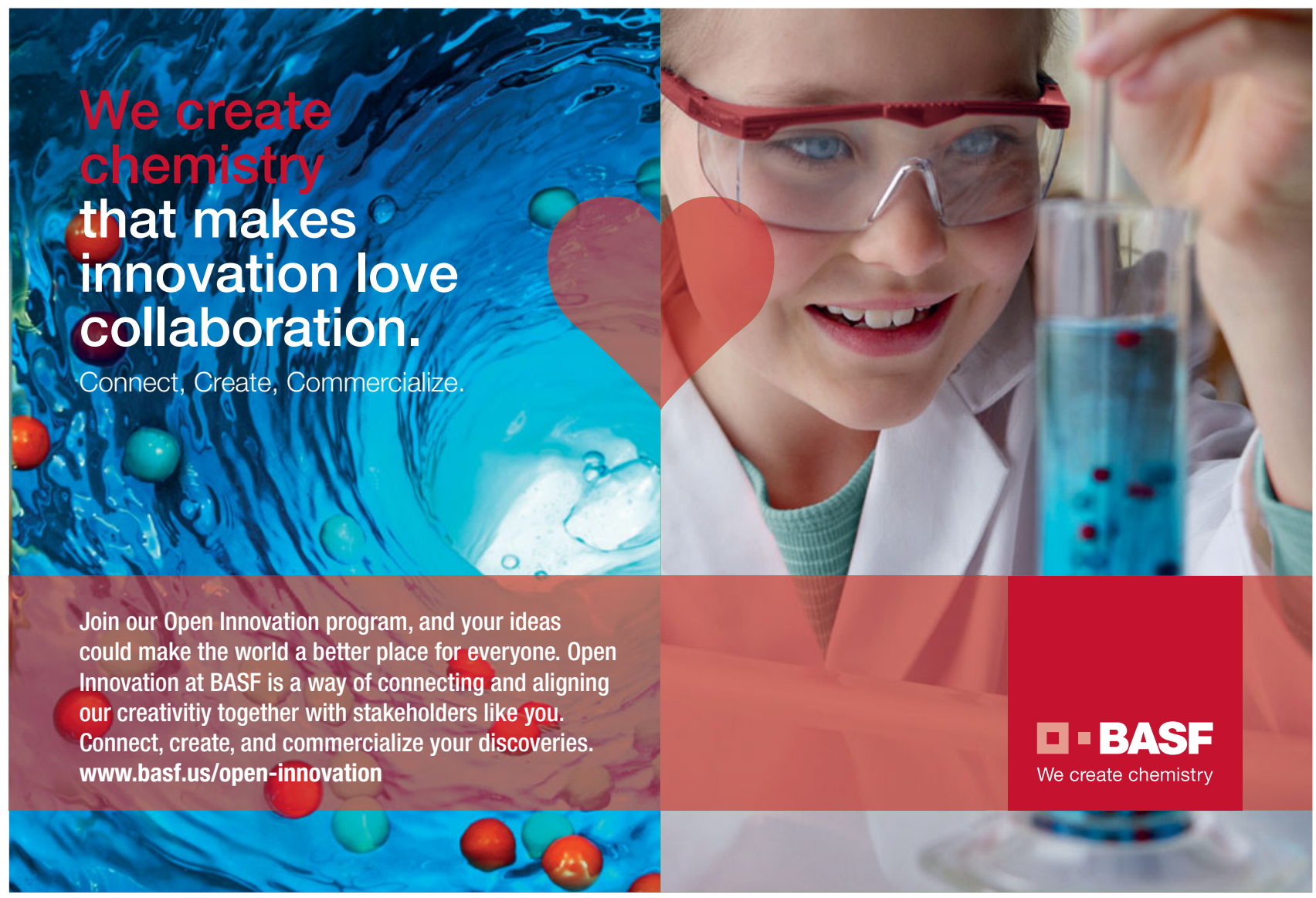




\section{ANNUAL REVIEWS *米 SPARK A CONNECTION}

You rely on Annual Reviews journals to intelligently synthesize the overwhelming volume of scientific literature and deliver the ideas and citations that will advance your research further, faster. Since 1932, our invited experts have cut out the noise to save you valuable research time.

\section{Order Today and Save $\mathbf{2 0 \%}$ on All Annual Reviews Journals}

Contact Customer Service (650) 493-4400 to place your order. Please mention priority code MRS.

Handling and applicable sales tax additional.

\section{Annual Reviews Physical Science Journals:}

- Annual Review of Analytical Chemistry

anchem.annualreviews.org | VOL 8 | JUL 2015

- Annual Review of Astronomy and Astrophysics astro.annualreviews.org | VOL 53 | SEPT 2015

- Annual Review of Biomedical Engineering bioeng.annualreviews.org | VOL 17 | AUG 2015

- Annual Review of Biophysics biophys.annualreviews.org | VOL 44 | JUN 2015

- Annual Review of Chemical and Biomolecular Engineering chemeng.annualreviews.org | VOL 6 | JUL 2015

- Annual Review of Condensed Matter Physics condmat.annualreviews.org | VOL 6 | MAR 2015

- Annual Review of Earth and Planetary Sciences earth.annualreviews.org | VOL 43 | MAY 2015
- Annual Review of Environment and Resources energy.annualreviews.org | VOL 40 | NOV 2015

- Annual Review of Fluid Mechanics fluid.annualreviews.org | VOL 47 | JAN 2015

- Annual Review of Marine Science marine.annualreviews.org | VOL 7 | JAN 2015

- Annual Review of Materials Research matsci.annualreviews.org | VOL 45 | AUG 2015

- Annual Review of Nuclear and Particle Science nucl.annualreviews.org | VOL 65 | NOV 2015

- Annual Review of Physical Chemistry physchem.annualreviews.org | VOL 66 | MAY 2015

- Annual Review of Statistics and Its Application statistics.annualreviews.org | VOL 2 | MAR 2015

Access all Annual Reviews journals via your institution at www.annualreviews.org 